\title{
N2a Stage Finding
}

National Cancer Institute

\section{Source}

National Cancer Institute. N2a Stage Finding. NCI Thesaurus. Code C48711.

A general term that refers to a TNM finding of cancer metastases in several regional lymph nodes. The definition of N2a TNM finding depends on the specific type of cancer that it refers to; for example, for breast cancer it refers to metastases in 4 to 9 axillary lymph nodes (at least 1 tumor deposit greater than $2.0 \mathrm{~mm}$ ); for cutaneous melanoma it refers to micrometastases in 2-3 regional lymph nodes; for colorectal cancer it refers to metastases in 4-6 regional lymph nodes. 